\title{
Personality Life Positions of Persons Living with HIV/AIDS in Kenya
}

\section{Emily Chepngetich Sitienei}

Department of Educational Psychology, Moi University, Eldoret, Kenya

"Corresponding Author: Dr. Emily Chepngetich Sitienei, Department of Educational Psychology, Moi University, PO Box 3900- 30100, Eldoret, Kenya, E-mail: emibensi@ gmail.com

Received: 01 October 2018; Accepted: 10 October 2018; Published: 15 October 2018

\begin{abstract}
HIV infection presents the victim with a broad range of personal psychosocial challenges that may transform their lives negatively. The pandemic can shift individual's personality life position from adaptive/healthy position to incongruent and maladaptive personality life position. This is due to the fact that personality is subject to change depending on life experiences. The purpose of this study was to assess personality life positions of persons living with HIV/AIDS (PLWHA). This study used a total of 75 HIV/AIDS positive participants out of which, 50 participants had attended psychological counseling for more than 12 sessions while 25 had not attended counseling at all. The study established psychological counseling has significant effect on changing the personality life positions of PLWHA especially those going through a lot of stress in trying to accept the reality of life. The study suggests that PLWHA should utilize psychological counseling in order to overcome maladaptive personality life position and live a normal irrespective of their current status.
\end{abstract}

Keywords: Personality life positions; Persons living with HIV/AIDS; Kenya

\section{Introduction}

Persons living with HIV/AIDS (PLWHA) who find it hard to accept HIV/AIDS infection usually resort to socially unacceptable way of life. They tend to project their hurting feelings to other members of the society and hence they adopt new type of personality which is situational in nature. The stigma associated with HIV/AIDS poses a psychological challenge to people living with HIV/AIDS [1]. Infected, and in some cases, affected, people can experience a decrease in self-esteem as they are no longer confident in themselves or what they can achieve [2]. This is mainly due to stigma within society on infected and affected people where they are seen as lesser persons and are at times devalued. In his Transactional Analysis theory, Berne [3] stated that our adult pattern of behaviour 
originated from our childhood experiences based on life scripts that people continue to replay their childhood strategies to face life challenges even if these strategies are painful [4]. Personality refers to the pattern of thoughts, feelings, social adjustments, and behaviors consistently exhibited over time that strongly influences one's expectations, self-perceptions, values, and attitudes and it also predicts human reactions to other people, problems, and stress [5-6].

Most theorists agree that both traits and situational factors are important in determining personality type, with aggregate behavior being primarily determined by traits and situational factors as the primary predictor of behavior in the short term [7-9].

Corey [10] pointed out that people have the ability to become aware of decisions that govern their behaviour and of the capacity to make new decisions that will beneficially alter the course of their life. For this study, it implies that the PLWHA have the capacity to make new decision about their current unhealthy personality life positions and be able to live happy lives irrespective of their health status. Transactional Analysis has the emphasis that people have the capacity to transform their distorted feelings in a positive manner by changing their way of thinking and reasoning [11]. Many researchers have attested that personality of an individual is likely to change any moment depending situational factors [7, 9, 12-15]. They propose that personality consists of differences between individuals in how they react to situations, rather than in general ways of acting (traits). Reacting to situation is primary and psychologists should study the processes whereby people react to changing situations [9]. Mental health professionals working with people who are HIV positive should consider how their clients cope with HIV/AIDS stigma and consider tailoring therapies to address the relationship between stigma, coping, and psychological wellbeing [1]. It is with this view that this study envisaged to assess personality life positions of PLWHA and to shed light on factors that might have made them to hold such positions and also show how counseling can be used to transform incongruent and maladaptive personality life positions to adaptive personality life positions.

\section{Method}

\subsection{Participants}

The study used a total of 75 HIV/AIDS positive participants to take part in the study. From this group of participants, 50 participants had attended psychological counseling for more than 12 sessions while 25 participants had not attended counseling at all.

\subsection{Instruments}

This study used unstructured questionnaire and interview to collect data. The items in unstructured questionnaire were 5 in number intended to ascertain the personality life positions of the participants. The unstructured questionnaire was preferred because it provided firsthand information from the sample [16]. It also gave the participant a chance to respond to the items freely since the issues pertaining HIV/AIDS are usually very sensitive especially if face to face questions are asked. 


\subsection{Data collection procedure}

The researcher obtained the permit from through the National Council for Science and Technology in Kenya. Through the administration of the organizations, the researcher introduced herself to the psychological counselors who in turn assisted in identifying the PLWHA who were to take part in the study. The selected participants assented to the study and were assured of utmost confidentiality during and after the interview. Participants were given unstructured questionnaire where they were to describe their current personality life positions based on their current health status. The participants were requested not to write their names on the questionnaire. They were given enough time to answer the questions showing how they feel about their current life status.

\section{Results}

Data from unstructured questionnaire was analyzed by categorizing PLWHA according to their personality life positions. The study established that out of 75 PLWHA, 34 have accepted their health status and they are in Type I personality life position. Out of this 34 , a total of $64 \%(\mathrm{~N}=32)$ are those who had been counseled while $8 \%(\mathrm{~N}=2)$ were those who had not been counseled. The PLWHA who had irrational thoughts fall in category of Type II personality life position those of "I am OK, you not OK" and "I am not OK, you OK". These participants were 27 out of which $30 \%(\mathrm{~N}=15)$ had been counseled while $48 \%(\mathrm{~N}=12)$ had not been counseled. While others believe other people are $\mathrm{OK}$ and themselves they are not ok. They view their own selves as the victims to be blamed for their current health. The last group of participants based on personality life position was those in despair. They were 14 participants and out of which, $6 \%(\mathrm{~N}=3)$ had been counseled while $44 \%(\mathrm{~N}=11)$ had not been counseled. These individuals had adopted a maladaptive personality life position and they needed psychiatric interventions so that they could be able to come in terms with reality of HIV pandemic.

\section{Discussion}

Based on the above analyses, presentations and interpretation of data, the study established that psychological counseling has significant effect on the personality life positions of PLWHA. It was realized that the PLWHA who had gone for psychological counseling had adaptive personality life position as compared to those who had not gone for psychological counseling. The PLWHA who had not gone for psychological counseling had incongruent personality traits and others had maladaptive personality traits. These were the PLWHA who had not accepted their HIV/AIDS status and they were still in the state of denial. They stand on "I am OK- You are OK" personality life position and they believe that people have based on basic value, worth and dignity as human beings [17]. This position is characterized by an attitude of trust and openness, willingness to give and take and the acceptance of others as they are. In this study PLWHA can attain this position once they have dealt with their self-defeating effects of HIV/AIDS especially after going through psychological counseling [18]. The findings revealed that $64 \%(\mathrm{~N}=32)$ of counseled and $8 \%(\mathrm{~N}=2)$ of uncounseled PLWHA held adaptive personality life position. This implies that through the help of psychological counseling, the PLWHA may learn to accept themselves and others the way they are and they are open to new ways that can change their lives. Their regular contact with psychological counselor helps them to analyze their feeling and emotions and at the long run, they are able to overcome difficult and challenging stigma of HIV/AIDS. Since transactional analysis, is more of interactive therapy, both psychological counselor and PLWHA are able to disclose the trauma of HIV/AIDS and go in-depth in uncovering hidden potentials of living positively. 
The second personality life position is that of "I am OK- You are not OK" and "I am not OK - You are OK". It was realized that $30 \%(\mathrm{~N}=15)$ had been counselled while $48 \%(\mathrm{~N}=12)$ had not been counselled. While others believe people are $\mathrm{OK}$ and themselves they are not. They view their own selves as the victims to be blamed for their current health. This could be attributed to the fact that the HIV pandemic continuously affects the thinking capacity of PLWHA because it is a pandemic which is incurable. These individuals are in state of depression and they believe that other people are $\mathrm{OK}$ and that they are not OK. These are individuals who are depressed and they project their irrational thoughts and feelings on others [17]. They blame other people for their current health condition. This kind of irrational thought is found in people who hold good positions in the society because they feel they can deal with their problems without the help of other people [19-20]. They victimize themselves as the cause of their current health condition, develop low self-concept and they may not feel like being in company of other people [21]. They are full of anger, disgust and scorn on other people whom they view as inferior [22].

For this study, the PLWHA are likely to become aggressive and bitter and may blame others as the cause of their current health status. But it is important to understand that individuals in this kind of situation have a destiny and can be able to attain it if they are ready to redesign their own way of life. PLWHA who hold incongruent life position remain locked in denial stage and they usually use their disgust as defence mechanism like criticizing other people in public and pinning them down because they feel they are more superior to others [23]. They even go into depression after realizing their health status and they start feeling powerless [21]. If they have families, they concentrate on the lives of their children and neglect their health needs [22]. Individuals in this state can be able to free themselves from inappropriate, inauthentic and displaced emotions and be able to attain autonomous life that is spontaneous and full of capacities to solve life threatening problems [24]. It takes the efforts of psychological counsellor to help PLWHA to come in terms their state of health. Psychological counsellor needs to use confrontation skills to help these individual accept their current health conditions and change the way they view their lives.

The last position is that of "I am not OK- You are not OK". This is a maladaptive personality life position that is usually used by individuals who have despaired in their lives [3-4]. In this study, 14 participants held the maladaptive personality life position. Out this 14 , it was observed that $6 \%(\mathrm{~N}=3)$ had been counseled while $44 \%$ $(\mathrm{N}=11)$ had not been counseled. The PLWHA in this maladaptive state have lost interest in and hope in life. This is the worst position to be in as it means that one is in a terrible state and can easily resort to suicidal tendencies if no interventions are provided. Stigmatization and isolation by other members make them go into depression and hence their self-concept, self-image and self-esteem are totally affected [25]. These PLWHA find it so hard to cope in social world and they tend to lock themselves in their own world [4]. They see the world as being cruel and they believe that there is nobody to be trusted in the world. These people are full of hatred and they commit passive suicide by denying themselves food or medications [26]. This stage is difficult to deal with in the life of PLWHA but it can be changed once these individual decide to change their destiny since all negative emotions are curable [27-30]. This state needs psychiatric interventions for them to change this personality life position and accept their health status. For this study, PLWHA with the help of psychological counselors have a chance to deal with their 
irrational thoughts, negative feelings and antisocial behavior. No matter how stressful HIV/AIDS pandemic can be, one can still live positively depending on willingness to transform their lives positively.

\section{Conclusion}

This study established that PLWHA have different ways of viewing their lives and their thoughts can be influenced by their life situations. Sometimes people tend to see others as they are Okay and others not Okay based on their perceptions and their life encounters. PLWHA hold different views about their lives and this make them to have different personality life positions. From these findings, the study realized that there is need to understand that personality life position is not static since it can shift from the being healthy to maladaptive. But with the help of psychological counseling, PLWHA can become autonomous in dealing with the internal and external factors of HIV/AIDS. An individual can change the irrational thinking of "I am not Okay" or 'You not Okay' to "I am Okay" and 'You are Okay'. Psychological counselor can assist PLWHA to transform their negative emotions and maladaptive personality life positions to positive. They can be assisted to redesign their lives positively and take the principle "I am Okay, You are Okay" attitude.

\section{References}

1. Varni SE, Miller CT, McCuin T, et al. Disengagement and engagement coping with HIV/AIDS stigma and psychological well-being of people with HIV/AIDS. Journal of social and clinical psychology 31 (2012): 123-150.

2. UNAIDS. Report on Global HIV/AIDS Epidemic, 2000. Geneva : UNAIDS. (2001).

3. Berne E. Transactional Analysis in Psychotherapy. New York: Grove Press. (1961).

4. Goulding MM. Transactional Analysis and Re-decision Therapy. In: Zeig JK. The Evolution of Psychotherapy. New York: Brunner/Mazel (1987): 285-299.

5. Winnie JF, Gittinger JW. An introduction to the personality assessment system. Journal of Clinical Psychology Monograph Supplement 38 (1973): 1-68.

6. Krauskopf CJ, Saunders DR. Personality and Ability: The Personality Assessment System. University Press of America, Lanham, Maryland. (1994).

7. Zayas V, Shoda Y. Three decades after the personality paradox: Understanding situations. Journal of Research in Personality 43 (2009): 280-281.

8. Engler B. Personality Theories: An Introduction. ( $8^{\text {th }}$ Edn) Boston, MA: Houghton Mifflin. (2008).

9. Fleeson W. Moving Personality beyond the Person-Situation Debate: The Challenge and the Opportunity of Within-Person Variability. Current Directions in Psychological Science 13 (2004): 83-87.

10. Corey G. Theory and Practice of Group Psychological counseling. Belmont, CA: Thomson Brooks/Cole. (2008).

11. Harris TA. I'm Ok-You are OK. New York: Avon books. (1996).

12. Larsen RJ. A process approach to personality psychology: Utilizing time as a facet of data. In: Buss DM, Cantor N. Personality psychology: Recent trends and emerging directions. New York: Springer-Verlag (1989): 177-193.

13. Funder DC, Colvin CR. Explorations in behavioural consistency: Properties of persons, situations, and behaviours. Journal of Perception and Social Psychology 60 (1991): 773-794. 
14. Goldberg LR. The development of markers for the Big-Five factor structure. Psychological Assessment 4 (1992): 26-42.

15. Fleeson W. Towards a structure- and process-integrated view of personality: Traits as density distributions of states. Journal of Personality and Social Psychology 80 (2001): 1011-1027.

16. Ary D, Jacobs LC, Razavieh A. Introduction to Research in Education. New York: Brace College. (1990).

17. Berne E. Principles of Group Treatment. New York: Oxford University Press. (1972).

18. NASCOP. Strategy to strengthen Home-Based care Access, sustainability and quality in Kenya in 20022008. Nairobi: National Aids Control Council. (2002).

19. Allen JR. Concepts, competencies and interpretive communities. Transactional Analysis Journal 33 (2003): 126-147.

20. Arnold TJ, Simpson RL. The effects of TA group on emotionally disturbed school-age boys. Transactional Analysis Journal 5 (1975): 238-241.

21. Barnette T, Whiteside A. AIDS in 21stc. Disease and Globalization. Balgrave: MacMillan. (2002).

22. Tudor K, Hobbes R. Transactional Analysis. In: Dryden W. Handbook of Individual Therapy. $\left(4^{\text {th }}\right.$ Edn $)$ London: Sage (2002): 239-265.

23. Bee H. The Impact of Health Beliefs, Attitudes, Norms, and Self-efficacy for Sun Protection. Health Psychology 19 (1994): 469-478.

24. Kenny WJ. Problem-student effects on teacher ego state behavior. Transactional Analysis Journal 11 (1981): 252-253.

25. ATLIS. Stigma, Isolation, and Discrimination and their impact on HIV serostatus disclosure: A global survey of 2,035 PLWHA. (2010).

26. Lyketsos CG, Treisman GJ. Mood Disorders in HIV infection. Psychiatric Manual 31 (2001): 45-49.

27. White M, White J. Talking TA. (WPATA). (1998).

28. Stewart I. Eric Berne: Volume 2 of Key Figures in Counseling and Psychotherapy. London: Sage Publications (1992).

29. Zalcman M. Games analysis and racket analysis: Overview, critique, and future developments. Transactional Analysis Journal 20 (1990): 4-9.

30. White J. TA in black junior college. Transactional Analysis Journal Bulletin 8 (1969): 103.

31. Bee H. The Impact of Health Beliefs, Attitudes, Norms, and Self-efficacy for Sun Protection. Health Psychology 19 (1994): 469-478.

Citation: Emily Chepngetich Sitienei. Personality Life Positions of Persons Living with HIV/AIDS in Kenya. Journal of Psychiatry and Psychiatric Disorders 2 (2018): 122-127.

(C)
Creative Commons Attribution (CC-BY) license 4.0 